\title{
Research on the Influence of Regulatory Policies of Shanghai Real Estate on the House Price-Based on the Empirical Study of VAR Model
}

\author{
Xiao Longkai ${ }^{1}$, Zhou Xiaoping ${ }^{1}$ \\ ${ }^{1}$ School of Government, Beijing Normal University, Beijing China, 100875
}

Keywords: House price, regulatory policies, VAR model, effectiveness of policies

\begin{abstract}
Research Contents: This paper analyzes the influence of regulatory policies of Shanghai real estate on the price of new houses in Shanghai from June of 2013 to December of 2017 by building VAR model and evaluates the effectiveness of regulatory policies. The policy of property purchase restrictions inhibits the rapid increase of house price in a short time, but does so little in a long time. Credit policy can affect house price in a timely and rapid manner. Monetary policy can have a far-reaching influence. House supply in the future and the change of current house price index have some bearing on psychological expectation of consumers. Shanghai municipal government should attach more importance to the establishment of long-term mechanism and guarantee the effectiveness of policies when regulating real estate market and inhibiting the rapid increase of house price.
\end{abstract}

\section{Introduction}

With the rapid development of national economy and real estate industry, China house price also shows a stable upward trend. The house prices in first-tier cities in recent ten years have all the more risen by an average of $10 \%$ a year. Beijing housing price-to-income ratio reaches up to 14.9 , far higher than the reasonable upper limit ${ }^{[1]}$. As for the rapid growth of house price, Chinese government has issued a series of macroeconomic regulatory policy to prevent house price from increasing, which makes real estate industry return to normal and sound development track. Shanghai begins to implement the policy of property purchase restrictions in 2011. However, under the ever-intensifying macroeconomic regulatory policy, the house price of Shanghai still increased for 31 months from August of 2014 to February of 2017 with the increase of over $74 \%$.

In reality, it is still a question whether the introduction of macroeconomic regulatory policy can control house price or not. The current research shows that the policy of property purchase restrictions can decrease the house price in current period but retaliatory price rebound will arise if the policy is cancelled in a short time ${ }^{[2]}$. Many scholars believe that the policy of lending curbs and purchase restrictions can decrease the short-term speculative investment behavior but in the long term the government's strong intervention in the market is against the law of market operation, which cannot fundamentally reduce the house price in a long run ${ }^{[3-5]}$. Du Jianhua adopts VAR model to conduct empirical test on the relationship between house price and land price ${ }^{[6]}$. Shen Qiang et al. construct VAR model and analyze the influence of the policy of property purchase restrictions on Xia'men real estate market from the perspective of life cycle ${ }^{[7]}$. These scholars verify the effectiveness of VAR model in the analysis of government's macroeconomic adjustment policies but hold different opinions on the conclusion of the effect of the policy of lending curbs and property restrictions.

Shanghai, as one of first-tier cities, has the highest house prices. Shanghai municipal government has issued the policy of lending curbs and property restrictions once again to prevent the house price from further irrational increase. However, how well does macroeconomic regulatory policies work on Shanghai house price and whether it can achieve the desired result, which is yet to answer. Therefore, this paper takes Shanghai house price and government's macroeconomic regulatory policies as its research object and constructs VAR model to test the influence of government's macroeconomic regulatory policies on house prices in order to provide reference for the government to formulate related government's macroeconomic regulatory policies. 


\section{Index Selection and Data Specification}

\subsection{Index selection}

The paper mainly focuses on Shanghai house price and government's macroeconomic regulatory policies, thus it should take these two factors into full and comprehensive consideration in selecting index and reflect the characteristics of Shanghai real estate market. Therefore, in the aspect of index selection, it should give priority to publicly available data, such as statistical yearbook, public database, industrial reports, etc., which are relatively easy to access to and large volume with high authenticity.

\subsection{Data specification}

This paper selects the average price of new houses in Shanghai from Anjuke ${ }^{1}$ to measure the house price(HP) of Shanghai. Government's macroeconomic regulatory policies can fall into economic means, legal means and administrative means. In the real estate market, the government usually adopts economic means and influences the whole market operation by regulating some macroeconomic factors. Besides the influence of macroeconomic factors, the status of demand and supply in real estate market is also an important factor to influence house price ${ }^{[7]}$. Investment quota of housing development, to some extent, can reflect the future status of demand and supply in real estate market. However, the government inhibits such demand through policies of purchase restrictions. By combining related references, this paper selects broad measure of money supply (M2) and house loan interest rate (R) to measure currency and credit and loan under the government's macroeconomic regulatory policies and measures the status of demand and supply of real estate by using investment ratio of housing development (HI) in Shanghai. Policy dummy variable (POLICY) shows the implementation of the policies of purchase restrictions in real estate industry. This paper mainly selects three strictest regulations and controls adopted by Shanghai municipal government in real estate market as policy dummy variable to study, including Seven Principles of $\mathrm{Hu}^{2}$ (P1)implemented in November of 2013, Nine Principles of $\mathrm{Hu}^{3}$ (P2) implemented in March of 2016 and Six Principles of $\mathrm{Hu}^{4}$ (P3) implemented in October of 2016. As the policy dummy variables, P1-P3 are recorded as 0 respectively before the implementation and recorded as 1 after the implementation. Due to the strong timeliness of policy regulations and the fluctuation of house price, this paper analyzes the data from June of 2013 to December of 2017 which are from statistical yearbook, official websites of banks and so on.

\section{The Construction and Analysis of the Model}

\subsection{Stationarity test of data}

In order to eliminate the differences of dimension and order of magnitude of samples, the three variables HP, M2 and HI will be processed for logarithms to guarantee the correctness of the model. Since the data that are chosen are time series data, they need to subject to stationarity test before analyzing them. Therefore, this paper uses Eviews 8.0 software to do unit root test of ADF on data. Test result reveals that $\log (\mathrm{HI})$ is stationary series but $\log (\mathrm{HP}), \log (\mathrm{M} 2)$ and $\mathrm{R}$ are stationary series after being processed by test for unit root in first difference, which requires further co-integration test for the variables in the model in order to examine whether there is a long-term equilibrium relationship among variables.

\footnotetext{
${ }^{1}$ Founded in January of 2007, Anjuke is the first platform for houses rent and sale service in China, specializing in the service of house rent and sale service.

${ }_{2}^{2}$ Since 2013, two-year stable period of Shanghai house price has ended followed by evident fluctuation. Against such backdrop, Shanghai issued stricter regulatory policies in November 2013, stipulating that if households in Shanghai buy a second house with a loan from a commercial bank, the initial payment ratio will be raised from $65 \%$ up to above $70 \%$. Property purchase restrictions adjust the number of years for non-household households to pay taxes or social insurance premiums. The number of year of "paying taxes or social insurance premiums for over 1 year in two years in the city" since the date of buying house is adjusted into "paying taxes or social insurance premiums for over 2 years in three years in the city". In addition, it also stipulates the increase of land supply.

${ }^{3}$ In March, 2016, Shanghai issued the strictest new policy on real estate. The number of year of paying taxes or social insurance premiums is raised into above 5 years of payment in a row.

${ }^{4}$ In October 2016, Shanghai issued new Six Principles of Hu in order to further strengthen the supervision on real estate market and the regulation on land supply.
} 


\subsection{Co-integration test}

Johansen and Juselius (JJ) co-integration test will be conducted in each variable in the model. The result shows that there is at least co-integration among multi-variables in default model under 5\% significance level. Rejection of null hypothesis that there is no co-integration indicates that there is a long-term equilibrium and stable relationship among the elements, which is suitable for further analysis.

\subsection{VAR model analysis}

VAR model estimation is then conducted. According to SC and AIC principles, optimal lagged differences in this paper are determined as the first difference. The confirmation of optimal lagged differences can reflect the dynamic characteristics of VAR model. With the help of Eview 8.0, VAR(1) model with first difference as its lagged difference is established and autoregression simulation analysis is conducted, which draws first-order autoregressive equation of price change of Shanghai real estate as follows:

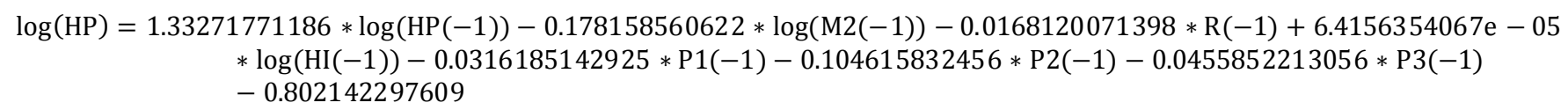

The result of VAR(1) model estimation is shown as follows. It is observed from autoregressive result that the fitting effect of the model is very good with $99.3 \%$ of $\mathrm{R}^{2}$, which indicates that the chosen variables can well explain the changes of average price of new houses of Shanghai. The result of model analysis can be used to evaluate the significance of each variable. And from the result, the degree of influence of each factor on Shanghai house price can be seen.

Table 1 the result of $\operatorname{VAR}(1)$ model estimation

\begin{tabular}{ccccccccc}
\hline & LOG(HP(-1)) & LOG(M2(-1)) & R(-1) & LOG(HI(-1)) & P1(-1) & P2(-1) & P3(-1) & C \\
\hline Coefficient & 1.33 & -0.18 & -0.02 & $6.42 \mathrm{E}-05$ & -0.03 & -0.10 & -0.05 & -0.80 \\
Standard & 0.11 & 0.11 & 0.01 & 0.02 & 0.02 & 0.03 & 0.02 & 1.79 \\
Deviation & 12.25 & -1.59 & -1.13 & 0.00 & -1.94 & -3.33 & -2.60 & -0.45 \\
T Statistic & & &
\end{tabular}

\subsection{Analysis of the result}

From table 1, we can see that the coefficient of house price in lagged first order among all factors in first order of time lag is the maximum number, reaching 1.33, which indicates that the house price of previous order has great impact on current house price provided that other conditions are invariant for the price of Shanghai new houses. In addition, it also indicates that the stickiness greatly features in the market price of Shanghai new houses. House buyers, to great extent, predicate future market price of houses according to the current house prices and buy houses when the prices are going up instead of going down. Moreover, broad measure of money supply has reverse influence on the house price of next order. Excess money supply will cause inflation. Capital in flowing into the real estate market will lead to raise in house prices. In three selected provisional regulatory policies, Nine Principles of Hu issued in March 252016 which is regarded as the strictest regulatory policy has played a significant role in inhibiting rapid increase of current house prices with its coefficient -0.1 . However, the investment quota of housing development has little influence on the house prices in next order, which is probably due to the development period in real estate industry. The increase of the investment quota of housing development cannot timely reflect the increase of supply.

\subsection{AR root diagram analysis}

In order to guarantee the stability of the result of the model, the paper conducts stability test of AR root diagram on VRA(1) model as shown in Fig. 1. From Fig. 1, we can see that all points are in the circle, which indicates that the model has strong stability. All characteristic roots of the model are in the unit circle, which shows that the establishment of VAR (1) has passed the test of stability with effective and reliable analysis results. 


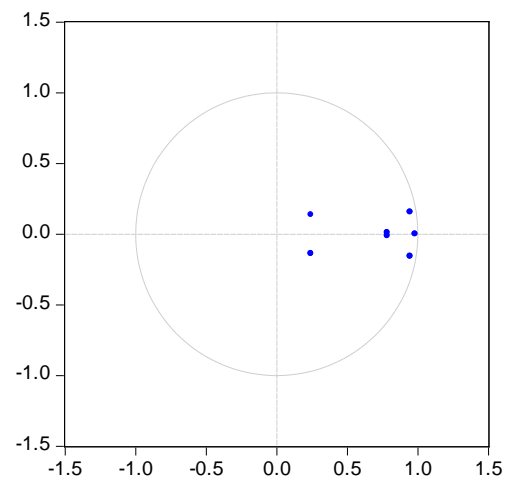

Fig. 1. AR root diagram of VAR (1)model

\subsection{Pulse response analysis}

In order to measure the influence of each variable on the house price of Shanghai in a long run, the paper conducts pulse response analysis which can examine the dynamic impact reaction of endogenous variables brought by one endogenous variable in VAR (1)model so as to describe the influence of long-term and mutual dynamic game of multiple factors. Impulse response function can measure the impact of random disturbance term on the track changes of disturbance degree of current value and future value of endogenous variables and directly and accurately describe dynamic interaction effect among variables in order to test the influence of the fluctuation of external variables on the house prices of Shanghai. In addition, the impact of broad measure of money supply (M2), house loan interest rate(R), investment quota of housing development in Shanghai (HI), Seven Principles of Hu (P1), Nine Principles of $\mathrm{Hu}$ (P2), and new Six Principles of Hu (P3) on the average price of new houses in Shanghai (HP) has been measured with its charts of pulse response as shown in Fig. 2.

Response of LOG(HP) to LOG(M 2)
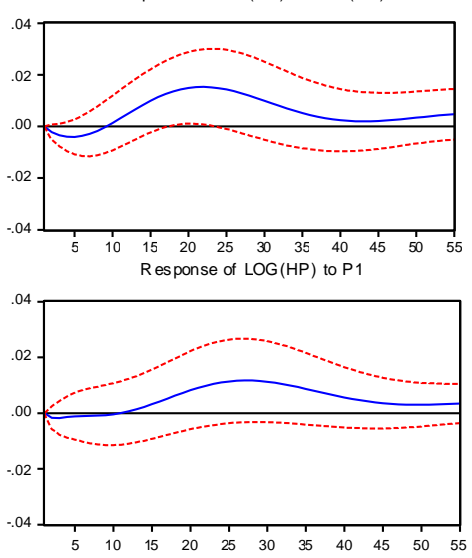

Response of LOG(HP) to LOG(HI)
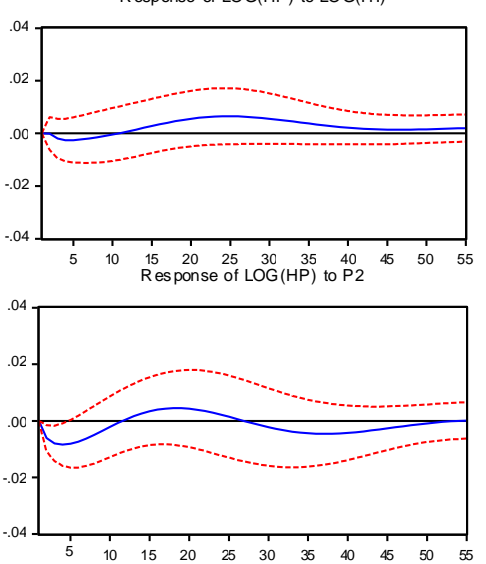

Response of LOG(HP) to $R$
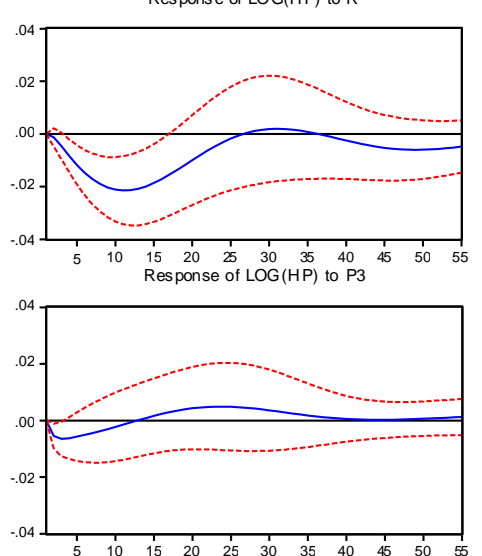

Fig. 2. Charts of pulse response of Shanghai average price of new houses

In Fig. 2, they are the charts of the influence of broad measure of money supply, investment quota of housing development, house loan interest rate, Seven Principles of $\mathrm{Hu}$, Nine Principles of $\mathrm{Hu}$, and new Six Principles of Hu on Shanghai average price of new houses respectively from left to right and from top to bottom. It is shown from Fig. 2 that the increase of money supply will cause the increase of Shanghai house prices in a very long term, which reflects that it has far-reaching influence with long duration.

However, the increase of investment quota of housing development will affect the supply-demand relationship in a short term, thus making the decrease of house prices. But after one development cycle (about 25 months), the positive influence on house prices peaks about $0.7 \%$. This impact brought by the increase of investment quota of housing development will gradual fade away after being absorbed by the market.

The rise of house loan interest rate will lead to intense reaction in the market as reflected in the sharp decrease of house prices, which indicates that the increase of loan interest rate makes the increase of the 
house- purchase cost and the decrease of the demand of house purchase. Its influence reaches its peak -2.1\% after about 12 months followed by slowly diminishing influence.

The influence of the policy of Seven Principles of Hu issued in November of 2013 on house prices can be nearly ignored in ten months, but such policy caused retaliatory increase of Shanghai house price after ten months, peaking at $1.2 \%$ in 26 months or so. Then its influence was gradually diminishing.

However, the implementation of Nine Principles of Hu issued in March of 2016 had immediate effect on Shanghai real estate market. The house prices decreased rapidly but such decrease only lasted about one year. It is shown that it can only have temporary effect on inhibiting the demand for houses relying on administrative means to regulate and control real estate market. And it does not work well in the long run.

The influence of Six Principles of Hu issued in October of 2016 is much weaker than Nine Principles of Hu. However, it played a certain role in preventing house price from rapid increase at that time. But it still shows worse effect in the long run.

\subsection{Variance decomposition analysis}

In order to make the contribution rate of each variable in different periods to the change of Shanghai house prices clear, the paper conducts variance decomposition analysis on VAR (1) model. Through variance decomposition analysis, the degree of importance of structural impact of different variables and relative size of the effect can be evaluated. Meanwhile, it can also analyze the time lag of the variable. The variance decomposition chart of Shanghai house price is shown in Fig. 3.
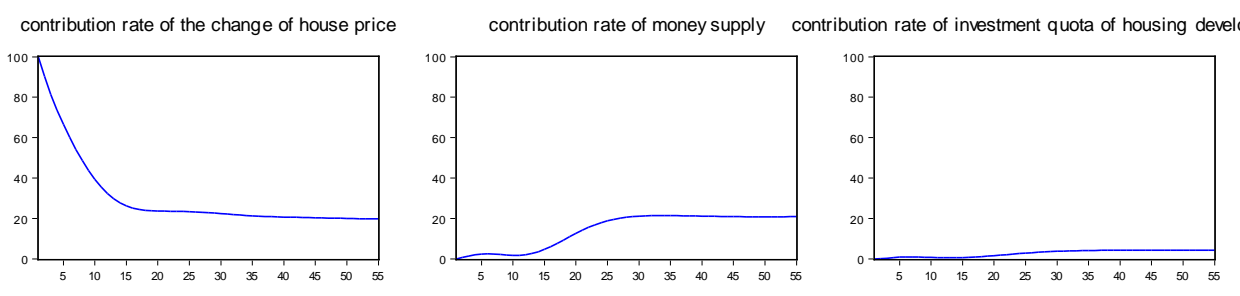

contribution rate of new Six Principles of $\mathrm{Hu}$

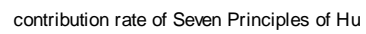

contribution rate of Nine Principles of $\mathrm{Hu}$
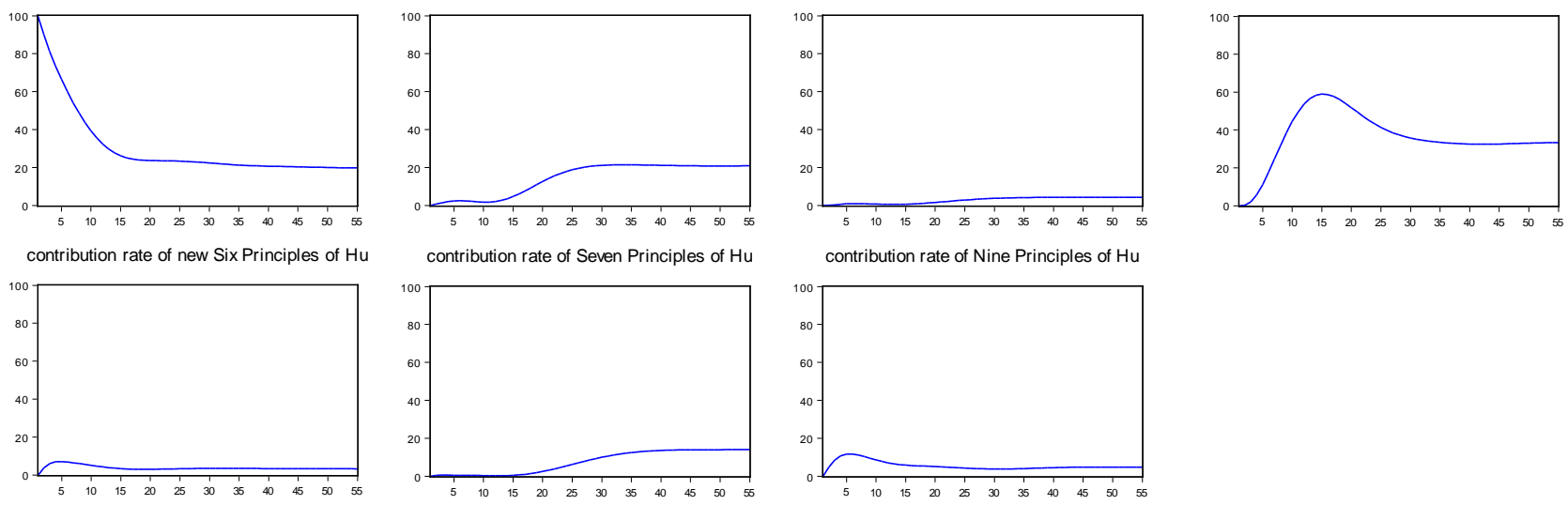

Fig. 3. The variance decomposition chart of Shanghai house price

The influence of lag phase on the current house price index in Shanghai is gradually diminishing to about $25 \%$ after 15 months and at last remains stable at about 25\%, which indicates that house prices is strongly featured by its inertia. Previous house prices continue to affect people's expectation, thus making house prices remain previous trend. However, the contribution rate of broad measure of money supply to the change of Shanghai house prices begins to show after 15 months and peaks in 25 months with 20\%, which reflects that the monetary regulatory policy lasts very long period with little effect. The contribution rate of investment quota of housing development to Shanghai house prices is relatively small, which is due to unbalance of supply and demand in Shanghai. Limited supply is inadequate to deal with the rapid increase of house prices. The contribution rate of house loan interest rate to the change of Shanghai house price plays a leading role from 15 months, finally remaining at about $32 \%$, which is caused by the relatively high unit price and total prices of Shanghai new houses. The change of interest rate will lead to huge change of total price, thus greatly affecting the house-purchase will of house buyers. Seven Principles of Hu contributes a lot to the rapid increase of house price in later period instead of showing its regulatory effect. However, Nine Principles of Hu and new Six Principles of Hu all affect the change of Shanghai house price in a short run and play a certain role in inhibiting the increase of house price, but they do not work well in the long run. 


\section{Conclusion and Suggestions}

In order to testify the effectiveness of regulatory policies on Shanghai real estate, this paper constructs VAR model to explore the influence of conventional means such as the supply of real estate, monetary policy and credit policy and temporarily-issued regulatory policies on Shanghai house prices. House loan interest rate and broad measure of money supply (M2) have far-reaching influence in the long run, which shows that monetary and credit policies issued by the government can effectively affect Shanghai house price. However, investment quota of housing development has little impact on Shanghai house price, which is due to severe unbalance of supply and demand in Shanghai real estate market. Limited supply cannot regulate Shanghai house price well. However, in a short time, appropriate regulatory policies can to some extent prevent the rapid increase of Shanghai house price, but inappropriate administrative regulatory policies will lead to retaliatory increase of house price.

Therefore, this paper proposes the following suggestions for regulating the housing market in Shanghai: (1) There is lag phase in Shanghai housing market. Current house price fluctuation can effectively affect house buyers' psychological expectation on future house price. When the housing market is expected to be depressed, house price will decrease; (2) Due to limited areas of Shanghai, it doesn't work well to regulate and control house price with the help of increasing supply. What the government needs to do is only to stabilize the supply; (3) Monetary and credit policies can regulate and control Shanghai house price in the mid and long run, therefore, the government can start out from regulating interest rate and decreasing money supply to stabilize house price; (4) Short-term regulatory policies on real estate, if appropriate, can only have limited effect in the short run and have poor effect in the long run. On the contrary, inappropriate regulatory policies will cause the rapid increase of house price.

\section{Reference}

[1]. Fan Chao, Wang Xueqi, Research on Permanent Income Ratio--the House Price of 35 Large and Medium-Sized Cities in China[J]. Statistical Research, 2016, 33(08):95-100.(In Chinese)

[2]. Liu Jiangtao, Zhang Bo, Huang Zhigang, On the Dynamic Change of the policy of Property Purchase Restrictions and House Price, 2012(3): 47-54. (In Chinese)

[3]. Tang Yun, Liang Ruobing, Why Purchase Restrictions Cannot Control House Price--Explanation from Marriage Market[J]. Economic Perspectives, 2016(11): 45-56. (In Chinese)

[4]. Feng Haining, It Would Rather Conduct Transition Than Bailout[J]. Review of Economic Research, 2014(66): 29-30. (In Chinese)

[5]. Yu Fenghui, Bailout is Hard to Prevent Real Estate Market from Falling[J]. Review of Economic Research, 2015(6): 28-28. (In Chinese)

[6]. Du Jianhua, Empirical Study on the Relationship Between House Price and Land Price Based on VAR Model[J]. Economic Research Guide, 2012, (7) (In Chinese)

[7]. Shen Qiang, Zhou Hong, Zhang Dongjie, Evaluation and Empirical Study of the Full Life Cycle of the Policy of Property Purchase Restrictions Based on VAR Model--A Case Study of Xia'men[J]. Journal of Engineering Management, 2017,31(04):148-153. (In Chinese) 